\title{
Suspensión de la patria potestad respecto al ejercicio de la tenencia legal de los bijos menores
}

\section{Suspension of the Parenthal Authority with Respect to the Legal Custody of the Minor Children}

Jessica Pilar Hermoza Calero* https://orcid.org/0000-0002-1460-1072 Luis Wigberto Fernández Torres** https://orcid.org/0000-0003-2318-1804

http://dx.doi.org/10.21503/lex.v17i23.1677

* Doctor en Derecho, magíster en Investigación y Docencia Universitaria, magíster en Derecho Civil por la Universidad Inca Garcilaso de la Vega (Lima, Perú), licenciada y bachiller en Educación Universidad Alas Peruanas (Lima, Perú), abogada, bachiller en Derecho, Universidad Inca Garcilaso de la Vega y bachiller en Educación de la Universidad Alas Peruanas. Conciliadora extrajudicial en familia. Docente a tiempo completo, Universidad Alas Peruanas.

Correo electrónico: j_hermoza@doc.uap.edu.pe; jessi_pilar0510@hotmail.com

** Doctor en Derecho, Universidad Alas Peruanas. Magíster en Derecho Penal, Universidad Alas Peruanas. Bachiller en Derecho y Ciencias Políticas y Abogado por la Universidad Inca Garcilaso de la Vega. Docente a tiempo completo, Universidad Alas Peruanas. Docente principal, Universidad Alas Peruanas.

Correo electrónico: 1_fernandez_t@doc.uap.edu.pe; luiswferto@yahoo.com
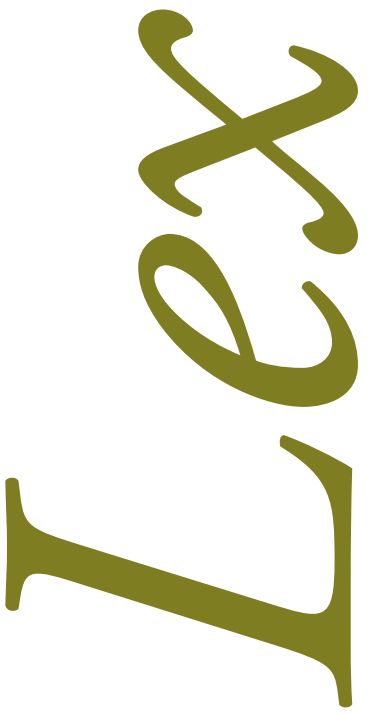


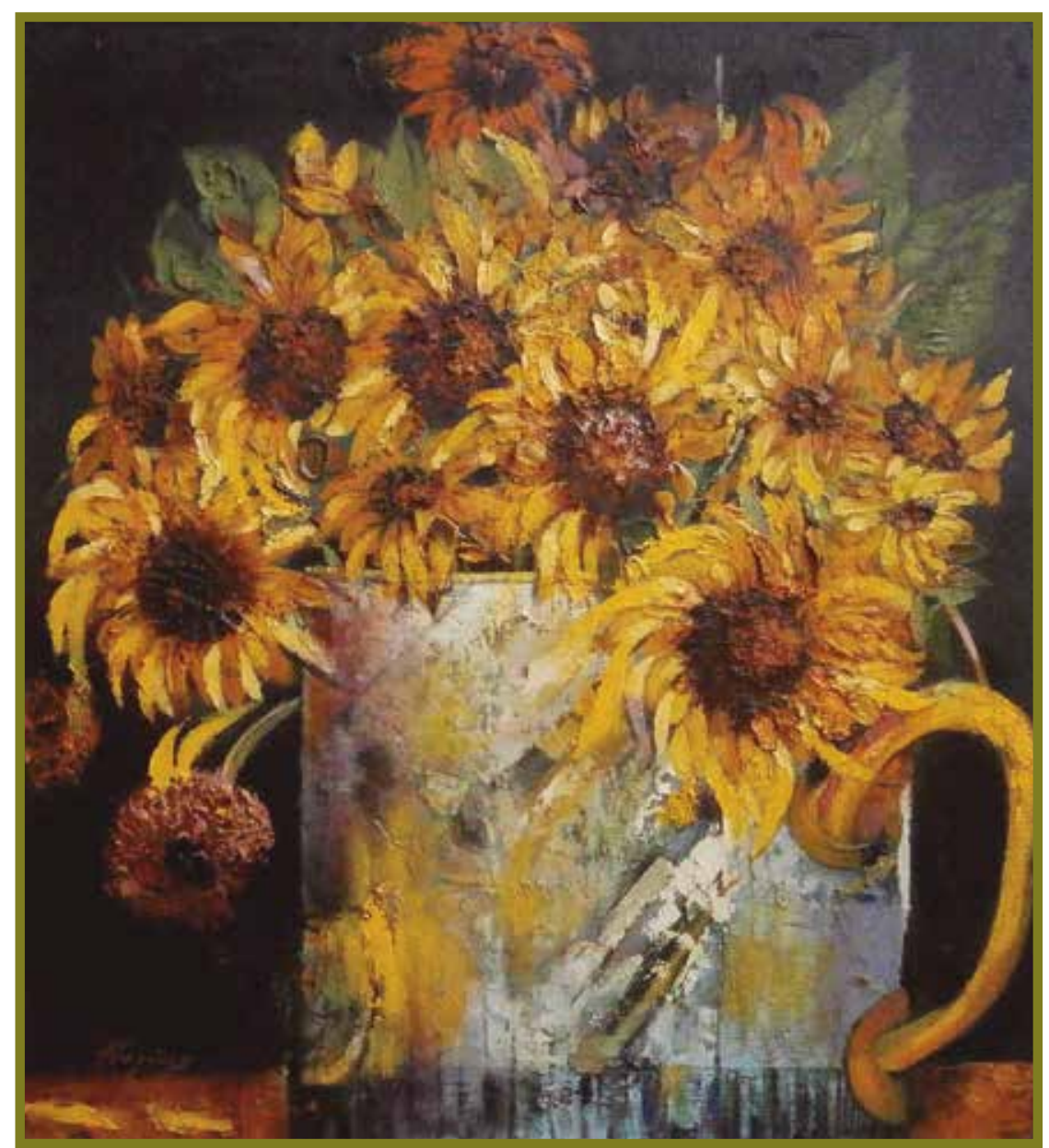

Girasoles. Óleo 48 x 45 cm.

Agustín Aquino Mejías (pintor peruano). 


\section{RESUMEN}

La presente investigación Suspensión de la patria potestad respecto al ejercicio de la tenencia legal de los hijos menores (Lima, 2016) ha tenido como objetivo determinar de qué manera la suspensión de la patria potestad restringe la tenencia legal de los hijos menores. La metodología es de tipo básica, el diseńo es no experimental-transversal, nivel descriptivo, el método fue inductivo, de enfoque cualitativo, la muestra fue de cuatro abogados en derecho de familia, el proceso de recolección de datos se realizó a través de una entrevista personal planteada. Se llegó a la conclusión de que normalmente la suspensión de la patria potestad se deriva de alguna sanción, mediante una sentencia, por ello resulta adecuado separar del entorno nocivo al menor y velar en todo momento en función del interés superior del menor.

Palabras clave: menor de edad, interés superior, patria potestad, tenencia, guarda y custodia compartida

\section{ABSTRACT}

The present investigation called Suspension of parental authority with respect to the legal custody of the minor children Lima, 2016 was aimed at determining how the suspension of parental authority restricts the legal custody of minor children. The methodology is of basic type, the design is non-experimental, transversal, descriptive level, the method is inductive, with a qualitative approach, the sample was four lawyers in family law, the data collection process was a personal interview, resulting in the following conclusion: the suspension of parental authority is commonly derived from a punishment ordered by means of a sentence, and therefore it is appropriate -in the best interest of the minor- to separate the minor from the harmful environment.

Key words: minor, higher interest, parental authority; custody, joint custody. 


\section{INTRODUCCIÓN}

La suspensión de la patria potestad respecto al ejercicio de la tenencia legal de los hijos menores, implica que uno de los padres al quedar suspendido por orden judicial del ejercicio de la patria potestad, no va poder visitar a su hijo y no puede, en tanto se encuentre suspendido provisionalmente, tener derecho a solicitar la tenencia legal de su menor hijo. Al amparo de Código Civil peruano y el Código de los Niños y Adolescentes.

Para desarrollar este estudio se planteó el siguiente problema principal: ¿de qué manera la suspensión de la patria potestad restringe la tenencia legal de los hijos menores?

Y los problemas específicos son los siguientes:

a) ¿De qué manera la restitución de la patria potestad contribuye a la tenencia legal de los hijos menores?

b) ¿Cómo el marco legal de la patria potestad influye en la tenencia legal de los hijos menores?

c) ¿De qué manera la tenencia compartida se afecta por la suspensión de la patria potestad?

Se trabajó con el siguiente supuesto: la suspensión de la patria potestad sí restringe el ejercicio de la tenencia legal de los hijos menores.

Respectivamente, con la siguiente categoría general: la patria potestad respecto a la tenencia legal de los hijos menores.

Por la patria potestad, los padres tienen el deber y el derecho de cuidar de la persona y bienes de sus hijos. En el primitivo derecho romano, el poder del pater familias era absoluto y recaía entre personas y cosas. ${ }^{1}$

1 Xavier O' Callagan Muñoz, Compendio de derecho civil, tomo IV, Derecho de la persona y de la familia (Madrid: Editorial Universitaria Ramón Areces, 2016), 368. 
La tenencia es un término jurídico que se ejerce cuando los padres están separados y el juez determina con quién de los dos se queda el hijo para su cuidado.

\section{Subcategorías}

\section{La restitución de la patria potestad}

Los padres a quienes se ha suspendido el ejercicio de la patria potestad podrán pedir su restitución cuando cesa la causal que la motiva. El juez especializado debe evaluar la conveniencia de la restitución de la patria potestad en razón del principio del interés superior del Niño y del Adolescente.

\section{Marco de la patria potestad}

La patria potestad se puede definir como el poder que la ley otorga a los padres sobre los hijos menores de edad no emancipados, para proveer a su asistencia integral. ${ }^{2}$

La tenencia compartida o conjunta es uno de los medios de ejercicio de la autoridad, para aquellos padres que desean proseguir con la relación entre padres e hijos, aun cuando la familia se haya fragmentado. Es un llamado a los padres que viven separados para que ejerzan en conjunto esta responsabilidad.

Se debe tomar en cuenta el estudio del tema en cuestión, ya que es en salvaguarda del interés superior del menor y la igualdad entre hombres y mujeres en cuanto a asumir la responsabilidad sobre los hijos, ambos padres en beneficio de los menores. La continuidad de la convivencia del menor con ambos padres es indispensable para el desarrollo psicoemocional saludable del mismo. Sobre la tenencia compartida y sus modalidades se refiere lo siguiente ${ }^{3}$ :

La tenencia compartida, al ser fundamentalmente un convenio, necesita de la cooperación de ambos padres para lograr acuerdos y una comunicación asertiva. La pareja ha decidido separarse por lo que la tenencia compartida implica mejorar aquellos aspectos que no han funcionado en la relación, esta vez encaminados a mejorar su rol como padres, no como pareja.

La tenencia compartida no está establecida en la norma, es decir, el juez, a petición de parte, no puede otorgar la tenencia compartida. Sin embargo, si ambos progenitores deciden esta modalidad de custodia, el juez la podrá aprobar en sentencia. El artículo 106 del Código de los Niños y Adolescentes en el numeral primero establece que para confiar la tenencia se respetará lo que los progenitores acuerden: "1. Se respetará lo que acuerden los progenitores siempre que ello no perjudique los derechos del hijo o hija”.

Rodrigo Bercovitz Rodríguez Cano (coord.), Manual de Derecho Civil. Derecho de familia (Madrid: Bercal, 2007$), 225$. Johana Ponce Alburquerque, Familia, conflictos familiares y mediación (Madrid: Editorial Ubijus, 2017), 149. 


\section{MATERIAL Y MÉTODO}

El diseño es no experimental y transversal. Podría definirse como la investigación que se realiza sin manipular deliberadamente variables. Lo que hacemos es observar fenómenos tal y como se dan en su contexto natural, para después analizarlos. En la investigación no experimental, no es posible asignar aleatoriamente a los participantes o tratamiento. De hecho, no hay condiciones o estímulos a los cuales se expongan los sujetos del estudio.

El diseño de investigación transeccional o transversal es aquel que realiza el investigador para dar respuesta a su trabajo de investigación. Reúne información de un determinado tema y en un solo tiempo, cuyo fin significa también recolectar datos en un solo momento, en un tiempo único. Su finalidad consiste en describir variables y observar su acontecimiento en un tiempo debido.

La investigación no debe tener ninguna alteración de los hechos observados en su forma natural, que posteriormente vayan ser analizados. Estos deben ser seleccionados en forma específica sobre un grupo, participantes, etc., y no existe la posibilidad de que se realice aleatoriamente. Este estudio se realiza sobre hechos o situaciones existentes, sin que el propósito de la investigación sea variarlos o modificarlos al momento de recolectarlas.

\section{Tipo de investigación}

La presente investigación es de tipo básica. Es la que se realiza con la finalidad de producir nuevos conocimientos para ampliar y profundizar las teorías sociales. No está dirigida al tratamiento inmediato de un hecho concreto, ni a resolver una interrogante fáctica, sino que únicamente es una investigación para profundizar la información sobre las relaciones sociales que se producen en el seno de la sociedad. ${ }^{4}$

Consiste en la investigación de un hecho social que se produce en una determinada sociedad, con la finalidad de proponer nuevos conocimientos a las teorías existentes, esto a través de ampliaciones o modificaciones.

\section{Método de investigación}

Se ha aplicado el método inductivo. Este método se utiliza en una organización de razonamiento lógico, consiste en que la indagación de información parte de hechos particulares para llegar a conclusiones generales.

4 Sergio Carrasco Díaz, Metodología de la investigación cientifica (Lima: Editorial San Marcos, 2009). 


\section{Población}

Es conveniente extraer muestras representativas del universo. Se debe definir en el plan y, justificar, los universos de estudios, el tamaño de la muestra, el método a utilizar y el proceso de selección de las unidades de análisis. En realidad, pocas veces es posible medir a la población por lo que obtendremos o seleccionaremos y, desde luego, esperaremos que este subgrupo sea un reflejo fiel de la población. ${ }^{5}$

La población objeto del presente estudio, estuvo constituida por veinte abogados especialistas en Derecho Civil, con habilitación dentro de la competencia jurisdiccional en Lima.

\begin{tabular}{|c|c|c|c|}
\hline $\begin{array}{c}\text { DISTRITO } \\
\text { JUDICIAL }\end{array}$ & CATEGORÍA & ESPECIALIDAD & POBLACIÓN \\
\hline Lima-Centro & Abogados & Derecho Civil & 20 \\
\hline
\end{tabular}

Fuente: Juzgado de Lima-Centro

\section{Muestra}

La muestra es, en esencia, un subgrupo de la población. Se puede decir que es el subconjunto de elementos que pertenecen a ese conjunto definido en sus necesidades al que llamamos población.

En la presente investigación la muestra seleccionada tiene las siguientes cualidades: el distrito judicial (competencia jurisdiccional), la categoría, especialidad, experiencia como abogados de familia que se desempeñan en el Juzgado de Lima-Centro.

\begin{tabular}{|c|c|c|c|}
\hline $\begin{array}{c}\text { DISTRITO } \\
\text { JUDICIAL }\end{array}$ & CATEGORÍA & ESPECIALIDAD & POBLACIÓN \\
\hline Lima-Centro & Abogados & Civil - Familia & 4 \\
\hline
\end{tabular}

\section{Técnicas}

La técnica de recolección de datos permite concentrar la información a través de un sistema que trata sobre un fenómeno social que guarda relación con el problema de investigación. Para lo cual se presentan las siguientes técnicas:

5 César Augusto Bernal Torres, Metodología de la investigación, segunda edición (México: Pearson Educación, 2006). 


\section{La entrevista}

Es una conversación al menos entre dos personas, en la cual una es el entrevistador y la otra u otros son los entrevistados, quienes dialogan, con arreglo a ciertos esquemas o pautas, acerca de un problema o cuestión y con un propósito determinado. La entrevista reposa en gran medida sobre relatos verbales, es "la herramienta de excavar", para adquirir conocimientos sobre la vida social.

Es una forma de recabar la información proporcionada por un entrevistado y realizada por un entrevistador en forma directa, con la finalidad de tratar un tema específico en forma verbal.

\section{Instrumentos}

El investigador es el instrumento de recolección de los datos, se auxilia de diversas técnicas que se desarrollan durante el estudio. Es decir, no se inicia la recolección de los datos con instrumentos preestablecidos, sino que el investigador comienza a aprender por observación y descripciones de los participantes y concibe formas para registrar los datos que se van refinando conforme avanza la investigación. ${ }^{6}$

Se denomina a las diversas técnicas de recolección de datos realizado por el investigador y que no definido antes de la investigación; sino que debe ser establecido durante la investigación.

\section{Marco teórico}

H. Ramos Zavala realizó un trabajo en Ecuador titulado Tenencia de los hijos menores de edad luego del divorcio o separación encaminada a la tenencia compartida de los padres en la Universidad Central del Ecuador.

\section{Objetivo general}

Fundar la coparentalidad asociada al ejercicio de la paternidad contemporánea dentro de la elaboración de un paradigma de la tenencia compartida.

\section{Objetivos específicos}

Para el cumplimiento del objetivo general se han formulado una serie de objetivos específicos que permiten definir detalladamente los aspectos considerados en el análisis y la orientación de la propuesta contenida en la tesis, mismos que se describen a continuación:

6 Rodrigo Pulido Rodríguez, Margarita Ballen Ariza, Flor Zúñiga López, Abordaje hermenéutico de la investigación cualitativa, segunda edición (Colombia: Editorial Universidad Cooperativa de Colombia, 2007). 
1. Conocer las implicaciones y efectos de la paternidad no custodia de la familia después de la separación conyugal y las nuevas tipologías que estructuran la familia actual, asociadas a la paternidad contemporánea.

2. Identificar los cambios socioculturales de la paternidad y el rol socio-afectivo, los factores disociadores y las consecuencias sociales, asociadas a la paternidad contemporánea.

3. Determinar las consecuencias psicológicas del divorcio parental, las vivencias y reacciones conductuales de la paternidad no custodia frente a los efectos obstructores del vínculo y del rol psicoafectivo, asociados a la paternidad contemporánea.

En conclusión, la familia se encuentra definida en un sinnúmero de criterios, formas y conceptos, los mismos que han sido determinados desde distintas perspectivas, por consanguinidad, relación jurídica, convivencia, lazos sentimentales, entre otros. Por el gran número de concepciones existentes en nuestra sociedad, resulta muy difícil tener una apreciación única a esta institución denominada Familia. ${ }^{7}$

Nos señala el autor Gonzalo Hernández Cervantes que existe un lazo consanguíneo indesligable entre la familia en sentido estricto. Así los padres estén separados de hecho o de derecho, debe cumplirse con el deber de ejercer la patria potestad. Téngase en cuenta que cuando se habla de patria potestad es un derecho por igual que le corresponde a los padres sobre su hijo, para lo cual la ley prevé que si no hay acuerdo entre los progenitores de cuidar por el desarrollo de su hijo, el juez de familia decidirá una tenencia compartida, quiere decir que ambos padres ejercerán en conjunto la tenencia de su hijo y se distribuirán las obligaciones que deben cumplir, con la finalidad de cumplir con el principio rector del interés superior del menor.

Hernández realizó un trabajo en Espańa titulado "La pérdida de la patria potestad y el interés del menor" para obtener el grado de doctor en la Universidad Autónoma de Barcelona. El objetivo general es atender al interés superior del menor como se pretende en la jurisprudencia transcrita, ya que para considerar adecuadamente a dicho interés superior del menor es necesario que el juzgador cuente con elementos de convicción objetivos que revelen que la aplicación de la privación de la patria potestad redundaría en perjuicio del menor.

En conclusión, el Código Civil para el Distrito Federal actualmente presenta a la institución de la patria potestad como un vínculo jurídico, fundamentalmente surgido entre los progenitores y los hijos, generador de múltiples derechos y obligaciones en calidad de irre-

\footnotetext{
Héctor Raúl Ramos Zavala, "Tenencia de los hijos menores de edad luego del divorcio o separación encaminada a la tenencia compartida de los padres" (tesis, Universidad Central de Ecuador, provincia de Quito, 2014).
} 
nunciables, sobre bases de respeto recíproco y buen ejemplo. Por tanto, la patria potestad es una función derivada del propio vínculo familiar y encomendada a los progenitores, y reconocida y fortalecida por el derecho. ${ }^{8}$

El autor manifiesta categóricamente que es deber de los padres ejercer la patria potestad sobre sus hijos, toda vez que debe ser permanente, estén separados o viviendo juntos como familia, porque va a dar lugar a cumplir con el buen desarrollo en todo ámbito de su menor hijo. Asimismo, la ley señala que si un padre deja de ejercer la patria potestad de su menor hijo, puede correr el riesgo de que el progenitor que tiene la tenencia del hijo pueda solicitar al Juez de Familia la suspensión de la patria potestad y hasta la pérdida de la misma.

\section{Análisis de tablas}

\begin{tabular}{|l|l|}
\hline \multicolumn{1}{|c|}{ PREGUNTAS } & \multicolumn{1}{|c|}{ ESPECIALISTA 1 / RESPUESTAS } \\
\hline $\begin{array}{l}\text { 1) ¿De qué manera la sus- } \\
\text { pensión de la patria potes- } \\
\text { tad restringe la tenencia } \\
\text { legal de los hijos menores? }\end{array}$ & $\begin{array}{l}\text { El entrevistado opina que cuando uno de los padres no cumple con sus } \\
\text { derechos y obligaciones frente a su hijo, puesto que se tiene en cuenta el } \\
\text { interés superior del menor, que es lo fundamental. }\end{array}$ \\
\hline $\begin{array}{l}\text { 2) ¿La restitución de la } \\
\text { patria potestad garantiza la } \\
\text { tenencia legal de los hijos } \\
\text { menores? }\end{array}$ & $\begin{array}{l}\text { El entrevistado respondió que después de haber acreditado el padre la } \\
\text { inconducta que ya fue subsanada, es el juez quien va a declarar la resti- } \\
\text { tución, teniendo en cuenta que el padre estará en constante supervisión } \\
\text { por su propia familia. Si continúa su buena conducta frecuentemente, } \\
\text { sí es posible que garantice la tenencia de su hijo. }\end{array}$ \\
\hline $\begin{array}{l}\text { 3) ¿El marco legal de la } \\
\text { patria potestad influye en } \\
\text { la tenencia legal de los hi- } \\
\text { jos menores? }\end{array}$ & $\begin{array}{l}\text { El consultado manifiesta que sí. Las normas legales influyen en la tenen- } \\
\text { cia de los hijos, en razón a la buena conducta que puedan tener los } \\
\text { padres y la edad del menor. }\end{array}$ \\
\hline $\begin{array}{l}\text { 4) ¿De qué manera la } \\
\text { tenencia compartida se ve } \\
\text { afectada por la suspensión } \\
\text { de la patria potestad? }\end{array}$ & $\begin{array}{l}\text { El entrevistado respondió que en el caso de que uno de los padres fre- } \\
\text { puentemente esté incumpliendo con la tenencia compartida, por ejem- } \\
\text { madre, para no alterar su educación ni su alimento oportuno. }\end{array}$ \\
\hline
\end{tabular}

8 Gonzalo Hernández Cervantes, "La pérdida de la patria potestad y el interés del menor" (tesis doctoral, Universidad Autónoma de Barcelona, 2010). 


\begin{tabular}{|l|l|}
\hline \multicolumn{1}{|c|}{ PREGUNTAS } & \multicolumn{1}{c|}{ ESPECIALISTA 2 / RESPUESTAS } \\
\hline $\begin{array}{l}\text { 1) ¿De qué manera la sus- } \\
\text { pensión de la patria potes- } \\
\text { tad restringe la tenencia } \\
\text { legal de los hijos menores? }\end{array}$ & $\begin{array}{l}\text { El entrevistado contestó que normalmente la suspensión de la patria } \\
\text { potestad se deriva de alguna sanción, por ello resulta adecuado separar } \\
\text { al menor del entorno nocivo, en función del interés superior. }\end{array}$ \\
\hline $\begin{array}{l}\text { 2) ¿La restitución de la la } \\
\text { patria potestad garantiza } \\
\text { la tenencia legal de los } \\
\text { hijos menores? }\end{array}$ & $\begin{array}{l}\text { El consultado indica que no siempre, pueden existir casos en los cuales } \\
\text { la patria potestad se encuentra condenada (a los alimentos por ejem- } \\
\text { plo yencia la ejerce el otro padre o un tercero (los abuelos, por } \\
\text { ejemplo). }\end{array}$ \\
\hline $\begin{array}{l}\text { 3) ¿El marco legal de la pa- } \\
\text { tria potestad influye en la } \\
\text { tenencia legal de los hijos } \\
\text { menores? }\end{array}$ & $\begin{array}{l}\text { Manifiesta que sí, debido a que hay presunciones legales que podrían } \\
\text { alterar el interés superior del menor, como que se quede en tenencia de } \\
\text { la madre y esta no resulte idónea para su desarrollo. }\end{array}$ \\
\hline $\begin{array}{l}\text { 4) ¿De qué manera la la } \\
\text { tenencia compartida se ve } \\
\text { afectada por la suspensión } \\
\text { de la patria potestad? }\end{array}$ & $\begin{array}{l}\text { El entrevistado consideró que existen dos factores que la alterarían: el } \\
\text { primero respecto al régimen de visitas; el segundo a que de seguir jun- } \\
\text { tos, el menor no se estaría desarrollando en el ambiente más idóneo. }\end{array}$ \\
\hline
\end{tabular}

\begin{tabular}{|l|l|}
\hline \multicolumn{1}{|c|}{ PREGUNTAS } & \multicolumn{1}{c|}{ ESPECIALISTA 3 / RESPUESTAS } \\
\hline $\begin{array}{l}\text { 1) ¿De qué manera la sus- } \\
\text { pensión de la patria potes- } \\
\text { tad restringe la tenencia } \\
\text { legal de los hijos menores? }\end{array}$ & $\begin{array}{l}\text { De manera importante, debido a que, al tener la patria potestad, se } \\
\text { tiene el derecho de requerir la tenencia del menor en caso de separación } \\
\text { entre los padres. Al padre, al ser suspendido, se le limita la capacidad } \\
\text { de solicitarlo. }\end{array}$ \\
\hline $\begin{array}{l}\text { 2) ¿La restitución de l a } \\
\text { patria potestad garantiza la } \\
\text { tenencia legal de los hijos } \\
\text { menores? }\end{array}$ & $\begin{array}{l}\text { El entrevistado responde que no, porque son derechos totalmente dis- } \\
\text { tintos. Al restituir la patria potestad no se está dando el derecho a la } \\
\text { tenencia de los hijos, ya que la tenencia debe seguir un proceso total- } \\
\text { mente distinto. }\end{array}$ \\
\hline $\begin{array}{l}\text { 3) ¿El Marco Legal de la } \\
\text { patria potestad influye en } \\
\text { la tenencia legal de los hi- } \\
\text { jos menores? }\end{array}$ & $\begin{array}{l}\text { El consultado respondió que sí, ya que hay que recordar que para lograr } \\
\text { la tenencia legal de los hijos, se debe contar con la patria potestad de los } \\
\text { mismos, tener derechos y obligaciones sobre el menor. }\end{array}$ \\
\hline $\begin{array}{l}\text { 4) ¿De qué manera la } \\
\text { tenencia compartida se ve } \\
\text { afectada por la suspensión } \\
\text { de la Patria potestad? }\end{array}$ & $\begin{array}{l}\text { El entrevistado respondió que al suspender la patria potestad, ya sea el } \\
\text { padre o la madre, este va a perder el derecho a la tenencia legal, y por } \\
\text { tanto, la otra parte pasaría a tener la tenencia total, en caso de que la } \\
\text { requiera. }\end{array}$ \\
\hline
\end{tabular}




\begin{tabular}{|l|l|}
\hline \multicolumn{1}{|c|}{ PREGUNTAS } & \multicolumn{1}{c|}{ ESPECIALISTA 4 / RESPUESTAS } \\
\hline $\begin{array}{l}\text { 1) ¿De qué manera la sus- } \\
\text { pensión de la patria potes- } \\
\text { tad restringe la tenencia } \\
\text { legal de los hijos menores? }\end{array}$ & $\begin{array}{l}\text { Teniendo en cuenta que la suspensión de la patria potestad emana de } \\
\text { una sentencia, esta también puede limitar la tenencia porque hay cau- } \\
\text { sales para la suspensión. }\end{array}$ \\
\hline $\begin{array}{l}\text { 2) ¿La restitución de la pa- } \\
\text { tria potestad garantiza la } \\
\text { tenencia legal de los hijos } \\
\text { menores? }\end{array}$ & $\begin{array}{l}\text { No siempre, porque, el devolverle el título de padre significa en la prác- } \\
\text { tica, una vez que se restituye, que el padre va junto a su hijo, porque } \\
\text { legalmente está apto para ejercer la patria potestad de su hijo. }\end{array}$ \\
\hline $\begin{array}{l}\text { 3) ¿El marco legal de la pa- } \\
\text { tria potestad influye en la } \\
\text { tenencia legal de los hijos } \\
\text { menores? }\end{array}$ & $\begin{array}{l}\text { Claro que sí, la tenencia legal permite crear un ambiente condicional } \\
\text { entre el padre y el hijo. Ahora sabiendo que la patria potestad es una } \\
\text { figura legal, influye porque de no ser reconocido como padre no hay un } \\
\text { compromiso. }\end{array}$ \\
\hline $\begin{array}{l}\text { 4) ¿De qué manera la } \\
\text { tenencia compartida se ve } \\
\text { afectada por la suspensión } \\
\text { de la patria potestad? }\end{array}$ & $\begin{array}{l}\text { El término suspensión de la patria potestad significa delimitar la calidad } \\
\text { legal del padre o la madre, entonces al no haber una figura legal que } \\
\text { lo una al hijo, el padre o la madre ya no tiene la responsabilidad de } \\
\text { cuidarlo. La tenencia compartida es una forma de estar con el hijo, pero } \\
\text { al suspenderse, uno de los padres se desentenderá de la responsabilidad } \\
\text { de los alimentos. }\end{array}$ \\
\hline
\end{tabular}

\begin{tabular}{|l|l|}
\hline \multicolumn{1}{|c|}{ PREGUNTAS } & \multicolumn{1}{c|}{ ESPECIALISTA/ INTERPRETACIÓN } \\
\hline $\begin{array}{l}\text { 1) ¿De qué manera la sus- } \\
\text { pensión de la patria potes- } \\
\text { tad restringe la tenencia } \\
\text { legal de los hijos menores? }\end{array}$ & $\begin{array}{l}\text { Contestaron que normalmente la suspensión de la patria potestad se } \\
\text { deriva de alguna sanción, mediante una sentencia. Por ello, resulta ade- } \\
\text { cuado separar del entorno nocivo al menor y velar en todo momento en } \\
\text { función del interés superior del mismo. }\end{array}$ \\
\hline $\begin{array}{l}\text { 2) ¿La restitución de la pa- } \\
\text { tria potestad garantiza la } \\
\text { tenencia legal de los hijos } \\
\text { menores? }\end{array}$ & $\begin{array}{l}\text { Respondieron que no, porque son derechos totalmente distintos. Al } \\
\text { restituir la patria potestad no se está dando el derecho a la tenencia de } \\
\text { los hijos, ya que la tenencia debe seguir un proceso totalmente distinto. } \\
\text { Por lo que primero se tendrá que ejercer la patria potestad porque ha } \\
\text { sido restituido el derecho. Puede ser que ante la buena conducta en un } \\
\text { futuro de existir circunstancias el juez puede otorgar la tenencia, porque } \\
\text { es el padre de su hijo y } \\
\text { mantiene buena conducta. }\end{array}$ \\
\hline
\end{tabular}




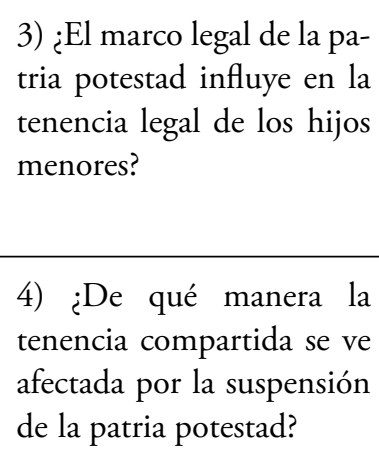

4) ¿De qué manera la tenencia compartida se ve afectada por la suspensión de la patria potestad?

Manifestaron que sí debido a que hay presunciones legales que podrían alterar el interés superior del menor, como que se quede en tenencia de la madre y esta no resulte idónea para su desarrollo. Para lograr la tenencia legal de los hijos, se debe contar con la patria potestad de los mismos, tener derechos y obligaciones sobre el menor.

Consideran que existen dos factores que la alterarían, el primero respecto al incumplimiento del régimen de visitas y el segundo a que de seguir juntos, el menor no se estaría desarrollando en el ambiente más idóneo, por lo que puede dar lugar a la variación de la tenencia compartida.

\section{Discusión de resultados}

\section{Primero}

En la presente investigación se determinó que normalmente la suspensión de la patria potestad se deriva de alguna sanción, mediante una sentencia. Por ello, según Hernández Cervantes resulta adecuado separar del entorno nocivo al menor y velar en todo momento en función del interés superior del mismo. Para sustentar lo anterior, este autor realizó un trabajo en Espańa titulado "La pérdida de la patria potestad y el interés del menor" para obtener el grado de doctor en la Universidad Autónoma de Barcelona. El objetivo general es atender al interés superior del menor como se pretende en la jurisprudencia transcrita, ya que para considerar adecuadamente a dicho interés superior del menor es necesario que el juzgador cuente con elementos de convicción objetivos que revelen que la aplicación de la privación de la patria potestad redundaría en perjuicio del menor. En conclusión, el Código Civil para el Distrito Federal actualmente presenta a la institución de la patria potestad como un vínculo jurídico, fundamentalmente surgido entre los progenitores y los hijos, generador de múltiples derechos y obligaciones en calidad d irrenunciables, sobre bases de respeto recíproco y buen ejemplo. Por tanto, la patria potestad es una función derivada del propio vínculo familiar y encomendada a los progenitores, y reconocida y fortalecida por el derecho. ${ }^{9}$

\section{Segundo}

Se determinó que la restitución de la patria potestad no garantiza la tenencia legal de los hijos menores, porque son derechos totalmente distintos. Al restituir la patria potestad no se está dando el derecho a la tenencia de los hijos, ya que la tenencia debe seguir un proceso totalmente distinto. Por lo que primero se tendrá que ejercer la patria potestad porque ha

9 Gonzalo Hernández Cervantes, "La pérdida de la patria potestad y el interés del menor" (tesis doctoral, Universidad Autónoma de Barcelona, 2010). 
sido restituido el derecho y puede ser que ante la buena conducta en un futuro, de existir circunstancias, el juez puede otorgar la tenencia, porque es el padre de su hijo y mantiene buena conducta. En contrastación a ello, ${ }^{10}$ la tesis de Silvana Morales Muñoz para la obtención del grado académico en Ciencias Jurídicas y Sociales de la Universidad de San Carlos de Guatemala tiene como objetivo principal dilucidar si es posible perder definitivamente el ejercicio de la patria potestad, por las personas que jurídicamente están designadas para esta tarea. Para el desarrollo del trabajo de investigación se utilizó una metodología cualitativa. El método a utilizar fue el inductivo, deductivo, analítico y sintético, debido a las actividades que se realizaron, tales como la interpretación contextual, la recolección de datos y la construcción de modelos teóricos de la explicación de los contenidos referentes al tema.

En conclusión, la patria potestad, es una institución cuya función principal es ser protectora de los hijos durante la minoría de edad, o bien cuando son mayores de edad y han sido declarados en estado de interdicción, lo que es una carga impuesta a quien debe ejercerla. Esta institución es la encargada de proteger la relación del menor de edad o al mayor de edad declarado en estado de interdicción, para la guarda y administración de su persona y de sus bienes, sin hacer distinciones entre hijos de matrimonio, fuera de matrimonio y adoptivos. En lo relativo a los efectos patrimoniales del ejercicio de la patria potestad, representados por la administración de los bienes de los hijos a ella sometidos, deben tenerse presente las limitaciones legales y garantías a constituirse en la administración de los padres para poder efectuar actos de enajenación y gravamen de los bienes pertenecientes a los hijos menores o incapacitados, pues los padres no pueden a su antojo exponer innecesariamente la pérdida total o parcial de dichos bienes.

\section{Tercero}

Manifestaron que si el marco legal de la patria potestad influye en la tenencia legal de los hijos menores, debido a que hay presunciones legales que podrían alterar el interés superior del menor, como que se quede en tenencia de la madre y esta no resulte idónea para su desarrollo. Para lograr la tenencia legal de los hijos, se debe contar con la patria potestad de los mismos, tener derechos y obligaciones sobre el menor. ${ }^{11}$ En contrastación a ello, Lida Suarez Loyola realizó un trabajo de investigación en Loja-Ecuador titulado Inconvenientes del régimen jurídico regulado por el código de la niñez y adolescencia respecto a la suspensión y pérdida de la patria potestad del menor para obtener el grado de Licenciada en Jurisprudencia en la Universidad Nacional De Loja. El objetivo era "realizar un estudio minucioso sobre el ejercicio de la patria potestad y la posibilidad de ampliar su comprensión para el correcto desempeño de la

10 Silvana Graciela Morales Muñoz, "La pérdida definitiva del ejercicio de la patria potestad” (tesis, Guatemala 2007).

11 Lida Suárez Loyola, "Inconvenientes del régimen jurídico regulado por el Código de la Niñez y Adolescencia respecto a la suspensión y pérdida de la patria potestad del menor" (tesis, Loja-Ecuador, 2010). 
misma”. Este objetivo fue verificado en el desarrollo del marco teórico donde se da a conocer la definición y evolución de la patria potestad.

Luego de una exhaustiva investigación, dentro de su desarrollo, tanto teórico como práctico, en forma minuciosa he analizado los diferentes contenidos, por lo que he concluido que la patria potestad es una institución jurídica encaminada a hacer respetar y velar por los derechos y facultades que la ley concede a los progenitores sobre sus hijos y sus bienes para permitirles el cumplimiento de sus obligaciones, ya que las funciones familiares parten de la comprensión y el respeto mutuo. La característica esencial de la patria potestad consiste en que los dos progenitores tienen a su cargo el cuidado, educación y desarrollo integral del menor, debido a que el hogar es donde el niño aprende sus primeros hábitos fiscos, intelectuales y morales.

\section{Cuarto}

Se considera que la tenencia compartida se ve afectada por la suspensión de la patria potestad y que existen dos factores que la alterarían, el primero respecto al incumplimiento del régimen de visitas y el segundo a que de seguir juntos, el menor no se estaría desarrollando en el ambiente más idóneo, por lo que puede dar lugar a la variación de la tenencia compartida. ${ }^{12}$

En contrastación a ello, Héctor Ramos Zavala señala en su tesis como objetivo general fundar la coparentalidad asociada al ejercicio de la paternidad contemporánea, dentro de la elaboración de un paradigma de la tenencia compartida.

Para el cumplimiento del objetivo general se han formulado una serie de objetivos específicos que permiten definir detalladamente los aspectos considerados en el análisis y la orientación de la propuesta contenida en la tesis, mismos que se describen a continuación:

1. Conocer las implicaciones y efectos de la paternidad no custodia de la familia después de la separación conyugal y las nuevas tipologías que estructuran la familia actual, asociados a la paternidad contemporánea.

2. Identificar los cambios socioculturales de la paternidad y el rol socio-afectivo, los factores disociadores y las consecuencias sociales, asociadas a la paternidad contemporánea.

3. Determinar las consecuencias psicológicas del divorcio parental, las vivencias y reacciones conductuales de la paternidad no custodia frente a los efectos obstructores del vínculo y del rol psicoafectivo, asociados a la paternidad contemporánea.

12 Héctor Raúl Ramos Zavala, “Tenencia de los hijos menores de edad luego del divorcio o separación encaminada a la tenencia compartida de los padres" (tesis, Universidad Central de Ecuador, provincia de Quito, 2014). 
En conclusión, la familia se encuentra definida en un sinnúmero de criterios, formas y conceptos, los mismos que han sido determinados desde distintas perspectivas, por consanguinidad, relación jurídica, convivencia, lazos sentimentales, entre otros. Por el gran número de concepciones existentes en nuestra sociedad, resulta muy difícil tener una apreciación única a esta institución denominada familia.

\section{CONCLUSIONES}

PRIMERA. Se determina que normalmente la suspensión de la patria potestad se deriva de alguna sanción, mediante una sentencia, por ello resulta adecuado separar del entorno nocivo al menor y velar en todo momento en función del interés superior del mismo.

SEGUNDA. No, porque son derechos totalmente distintos. Al restituir la patria potestad no se está dando el derecho a la tenencia de los hijos, ya que la tenencia debe seguir un proceso totalmente distinto. Por lo que primero se tendrá que ejercer la patria potestad porque ha sido restituido el derecho y puede ser que ante la buena conducta en un futuro, de existir circunstancias, el juez puede otorgar la tenencia, porque es el padre de su hijo y mantiene buena conducta.

TERCERA. Sí, debido a que hay presunciones legales que podrían alterar el interés superior del menor, como que se quede en tenencia de la madre y esta no resulte idónea para su desarrollo. Para lograr la tenencia legal de los hijos, se debe contar con la patria potestad de los mismos, tener derechos y obligaciones sobre el menor.

CUARTA. Sí existen dos factores que la alterarían, el primero respecto al incumplimiento del régimen de visitas, y el segundo a que de seguir juntos, el menor no se estaría desarrollando en el ambiente más idóneo, por lo que puede dar lugar a la variación de la tenencia compartida.

\section{RECOMENDACIONES}

PRIMERA. Realizar constantes charlas a los padres de familia para concientizarlos sobre cuáles son sus derechos del ejercicio de la patria potestad. En consecuencia, se evitarían tantos casos de menores que pueden quedar desamparados por un padre infractor suspendido para ejercer la patria potestad.

SEGUNDA. Una vez que un padre recupera el ejercicio de la patria potestad, debe designarse a un integrante de la familia o la obligatoriedad del consejo de familia para que fiscalice su buena conducta y de existir anomalías denunciarlo inmediatamente para que sea sancionado si reincide.

TERCERA. Si una vez que se ejerce la patria potestad por los padres que están separados, solo bajo esta condición se determina la tenencia, por lo que el Juez de Familia debería orde- 
nar que el padre que está a cargo de la tenencia pueda emitir un informe mensual para que comunique que está cumpliendo a cabalidad con el interés superior de su menor hijo.

CUARTA. Que mediante medios de comunicación se debe promover cuáles son los derechos de la tenencia del padre con sus hijos y el estricto cumplimiento de sus deberes.

\section{REFERENCIAS}

- Bernal Torres, César Augusto. Metodología de la investigación. Segunda edición. México: Pearson Educación, 2006.

- Callagan Muñoz, Xavier O'. Compendio de derecho civil. Tomo IV. Derecho de la persona y de la familia. Madrid: Editorial Universitaria Ramón Areces, 2016.

- Carrasco Díaz, Sergio. Metodología de la investigación cientifica. Lima: Editorial San Marcos, 2009.

- Hernández Cervantes, Gonzalo. "La pérdida de la patria potestad y el interés del menor". Tesis doctoral. Universidad Autónoma de Barcelona, 2010.

- Morales Muñoz, Silvana Graciela. "La pérdida definitiva del ejercicio de la patria potestad". Tesis, Guatemala, 2007.

- Ponce Alburquerque, Johana. Familia, conflictos familiares y mediación. Madrid: Editorial Ubijus, 2017.

- Pulido Rodríguez, Rodrigo; Margarita Ballen Ariza; Flor Zúñiga López. Abordaje hermenéutico de la investigación cualitativa. Segunda edición. Colombia: Editorial Universidad Cooperativa de Colombia, 2007.

- Ramos Zavala, Héctor Raúl. “Tenencia de los hijos menores de edad luego del divorcio o separación encaminada a la tenencia compartida de los padres". Tesis. Universidad Central de Ecuador, provincia de Quito, 2014.

- Rodríguez Cano, Rodrigo Bercovitz (coord.). Manual de Derecho Civil. Derecho de familia. Madrid: Bercal, 2007.

- Suárez Loyola, Lida. "Inconvenientes del régimen jurídico regulado por el Código de la Niñez y Adolescencia respecto a la suspensión y pérdida de la patria potestad del menor". Tesis. Loja-Ecuador, 2010.

RECIBIDO: $20 / 02 / 2019$

APROBADO: 25/05/2019 


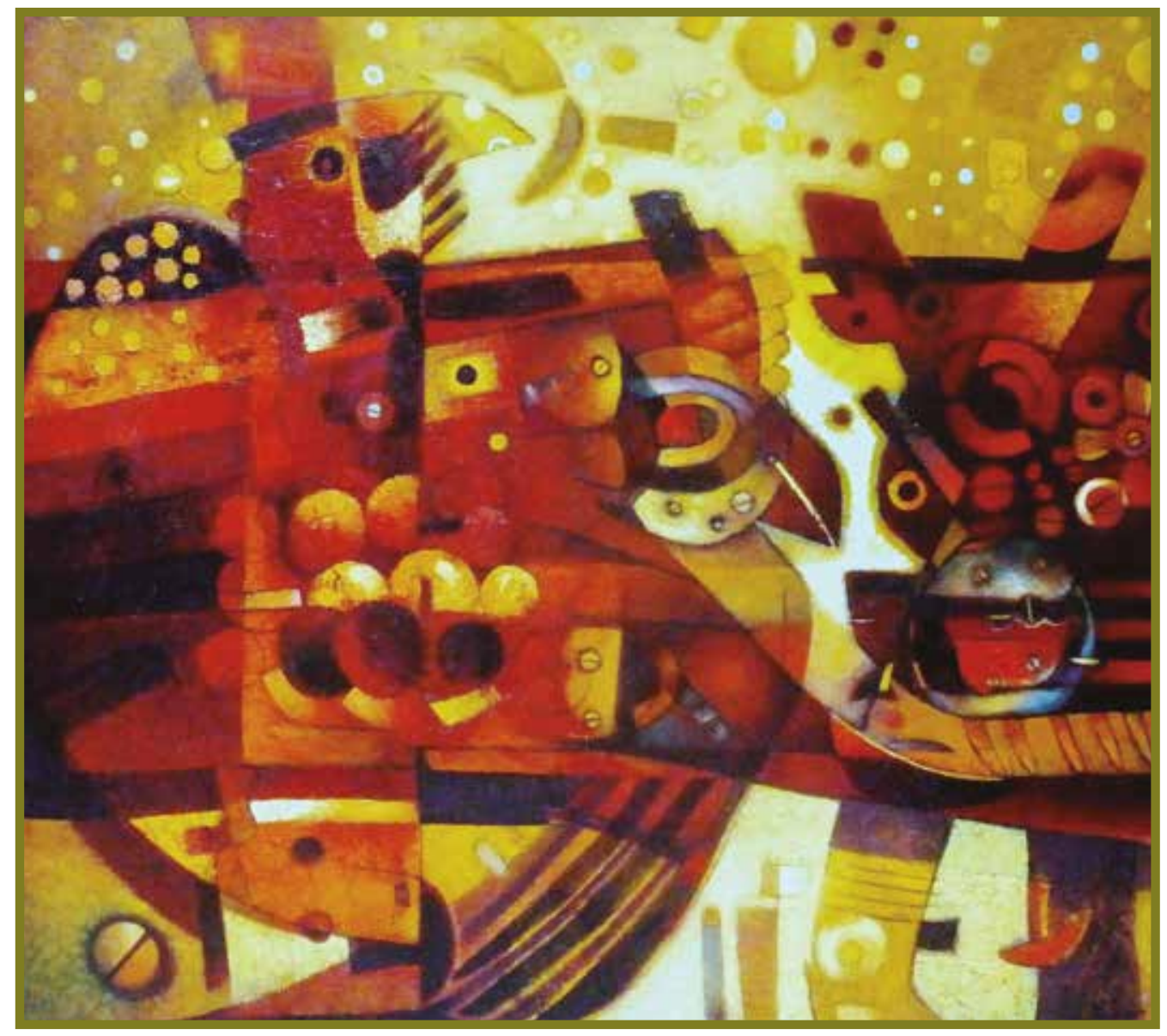

Yaguar fiesta. Óleo 90 x $100 \mathrm{~cm}$.

Agustín Aquino Mejías (pintor peruano). 